\title{
Development of an Isolated Small Wind Turbine Emulator
}

\author{
Md. Arifujjaman*, M.T. Iqbal and J.E. Quacioe \\ PO Box-100, Faculty of Engineering and Applied Science, Memorial University of Newfoundland, St. John`s, NL, AlB \\ $3 X 5$, Canada
}

\begin{abstract}
An isolated small wind turbine emulator based on a separately excited DC motor is developed to evaluate the performance of small wind turbine control strategies. The test rig consists of a 3HP separately excited DC motor coupled to a synchronous generator. A dump load is connected to the generator through a buck-boost converter controlled by a microcontroller. Wind turbine rotor and furling dynamics are incorporated in the emulator with the use of a PC based wind turbine model. Emulation of the wind turbine is achieved by running the DC motor to track the theoretical rotational speed of the wind turbine rotor. A dynamic maximum power controller is implemented and tested. The controller uses the wind speed and rotor speed information to control the duty cycle of the buck-boost converter in order to operate the wind turbine at the optimum tip speed ratio. Test results indicate that the proposed system accurately emulates the behavior of a small wind turbine system.
\end{abstract}

Keywords: Furling control, maximum power point, power electronics, wind turbine emulator.

\section{INTRODUCTION}

The abundance of renewable energy resources has encouraged the application of renewable energy systems to generate electricity. Electricity generation using wind power has undergone rapid advancement in the past several decades while, large-scale wind power generation systems are primarily used for community power, they are complex in operation and deploy a multitude of control methods. Smallscale wind power generation systems have the advantages of low visual impact, very few moving parts and ready deployment in remote and isolated locations.

Limiting the rotor power of a Small Wind Turbine (SWT) in high wind speed situations is a challenge. Active stall, passive stall, and pitch control are suitable options to reduce the aerodynamic power during high wind speed [1]. Indeed, these control schemes require significant understanding of the airfoil design which tends to increase the cost of the wind turbine. Passive pitching is another option for SWT systems, while Furling Control Method (FCM) has received major attention [2-5]. It is understood that the control of aerodynamic power by FCM does not ensure maximum power extraction; therefore a Maximum Power Controller (MPC) is also required along with the aerodynamic power control mechanism. In order to investigate the power electronics performance and MPC algorithm of a Wind Turbine (WT) in a laboratory environment the development of a Wind Turbine Emulator (WTE) is very important. A WTE can be used to investigate and fine-tune control strategies in a laboratory environment.

A WTE may use an AC or a DC motor to represent the WT rotor. Rresearchers more often choose an AC motor due

*Address correspondence to this author at PO Box-100, Faculty of Engineering and Applied Science, Memorial University of Newfoundland, St. John`s, NL A1B 3X5, Canada; Tel: (709) 737-2049; Fax: (709) 864-4042; E-mail:mda04@mun.ca, sumon326@yahoo.com to the advantage of large power and low price, however, the control method is comparatively complicated and rotor parameters are easy to change, hence speed or torque regulation and simulation accuracy are not pleasant $[6,12]$. On the other hand, from a control point of view, the DC motor presents a simple control approach by which the torque and speed can be controlled through the armature current [7-9]. Few researchers have considered the armature voltage control to operate the DC motor [10]. Although both armature voltage and current control methods have their own penetration into the field of emulator, however, armature voltage control method is preferred due to the fact that it does not change the speed regulation and speed is easily controlled from zero to maximum safe speed.

This paper proposes an isolated small WTE system which incorporates the high wind speed control and electronics for maximum power extraction. Furling control and the resulting dynamics for high wind conditions are incorporated with the use of a Personal Computer (PC) based wind turbine model. In order to represent the rotor dynamics, a large inertia disk is designed and coupled to the system. Dump load is connected to the generator through a microcontroller controlled DC-DC converter. To ensure maximum power extraction, a dynamic controller is developed which compares the actual Tip Speed Ratio (TSR) with an optimum TSR and uses the difference to control the Pulse Width Modulation (PWM) duty ratio of the buck-boost converter. A block diagram of the proposed emulator system is presented in Fig. (1).

This paper is organized as follows: The first section is a short overview of an emulator, and a synopsis of the associated literature review. In the second section, the modeling of a small wind turbine system with furling dynamics is presented and the proposed emulator is described. The emulator power electronics is discussed in the third section followed by the maximum power controller power electronics in the fourth section. The maximum power control algorithm is 


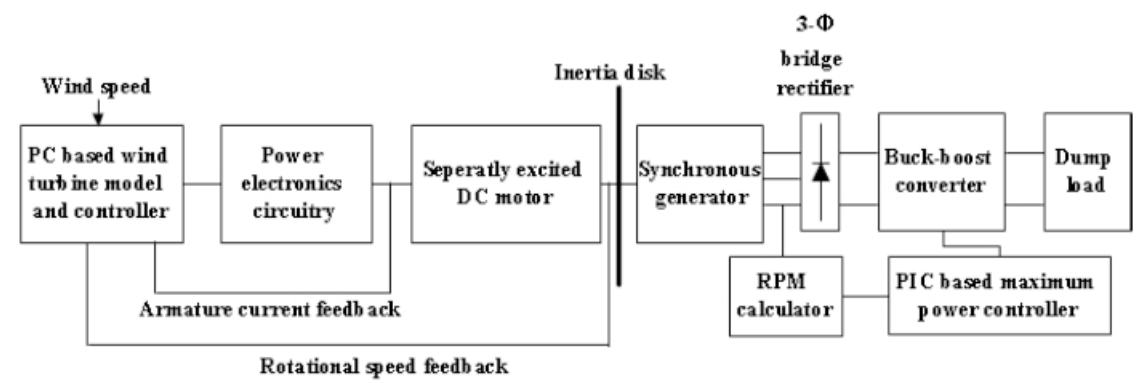

Fig. (1). Block diagram of the Wind Turbine Emulator system.

presented in the fifth section, and the sixth section contains test results. Finally, the findings of the investigations are highlighted in the conclusions.

\section{WIND TURBINE MODEL}

A wind turbine is a highly nonlinear system and to realistically represent a wind turbine, several dynamics should be included in the model to develop proper understanding of the dynamic behavior of the WT system. Several steady state wind turbine models have been investigated for the emulator platform based on the power/speed characteristics [11-13], torque coefficient characteristics [9, 10, 14], power coefficient and pitch angle characteristics [15]. However, static modeling is unable to reflect the different dynamic aspects of a wind turbine which is a crucial concern during operation. In published research, dynamic aspects are incorporated with the WT model using different approaches, including elastic model of the turbine shaft [16], mechanical balance equation for the turbine torque $[8,17]$, combination of the aerodynamic, oscillatory and dynamic torque [18]. Passive pitching mechanism and rotor blade inertia have been considered with the wind turbine model which leads to more generalized approach for a small wind turbine emulator system [7]. A review of research on the development of wind turbine emulator given by A. D. Diop, et al. [19], indicates that the furling action is still unexplored in the development of wind turbine emulator. In this work, the model of the WT employed in the emulator includes the nonlinearities and dynamics of a realistic wind turbine and the dynamics of the furling action and wind turbine rotor. As the wind turbine system considered is of the direct drive type, gear-box dynamics are not considered in the model. Rather, an inertia disk was added to the system to represent the inertia of the wind turbine rotor [20]. This represents a more practical approach compared to the approach that uses the inertia value in the controller algorithm [11].

A wind turbine can be characterized by the nondimensional curve of power coefficient $C_{p}$ as a function of tip speed ratio (TSR) $\lambda$, where, $\lambda$ is given in terms of rotor speed, $\omega_{m}(\mathrm{rad} / \mathrm{s})$, wind speed, $V(\mathrm{~m} / \mathrm{s})$, and rotor radius, $R$ $(\mathrm{m})$ and is expressed as

$\lambda=\frac{R \omega_{m}}{V}$

The relationship between $C_{p}$ and $\lambda$ is typical, and can be approximated by a quadratic equation. In this research, the curve is obtained from the literature [21]. A model for $C_{p}$ as a function of $\lambda$ is calculated, and the curves generated by the approximate model and the actual data are presented in Fig.
(2). Statistical analysis showed that the $R^{2}$ value of the model is $99.8 \%$ and the goodness of fit is less than 0.0001 , which shows that the predicted model for $C_{p}$ with the fitted coefficients is acceptable. The resulting equation is found to be

$C_{p}(\lambda)=0.00044 \lambda^{4}-0.012 \lambda^{3}+0.097 \lambda^{2}-0.2 \lambda+0.11$

The curve between wind speed and furling angle is also derived from published data [22, 23]. An approximate model is used to determine the relationship between wind speed and furling angle. It is found that a fifth order model is adequately represents the relationship. The $R^{2}$ value and goodness of fit of the expected model are found to be $98.59 \%$ and less than 0.0001 respectively, thus validating the modeling approach. The relationship between the furling angle and wind speed is represented by

$$
\begin{aligned}
& \theta=-0.00017327 V^{5}+0.0085008 V^{4}-0.12034 V^{3} \\
& +0.4501 V^{2}+1.0592 V+0.38972
\end{aligned}
$$

The curves of the actual data and approximated model curve represented in Fig. (3).

The furling action should be achieved within a reasonable time and it is assumed that the furling action would take 10 seconds to attain the WT rotor in its stable state [24]. The second order dynamics for this furling action is considered as

$$
H(s)=\frac{1}{1.3 s^{2}+s+1}
$$

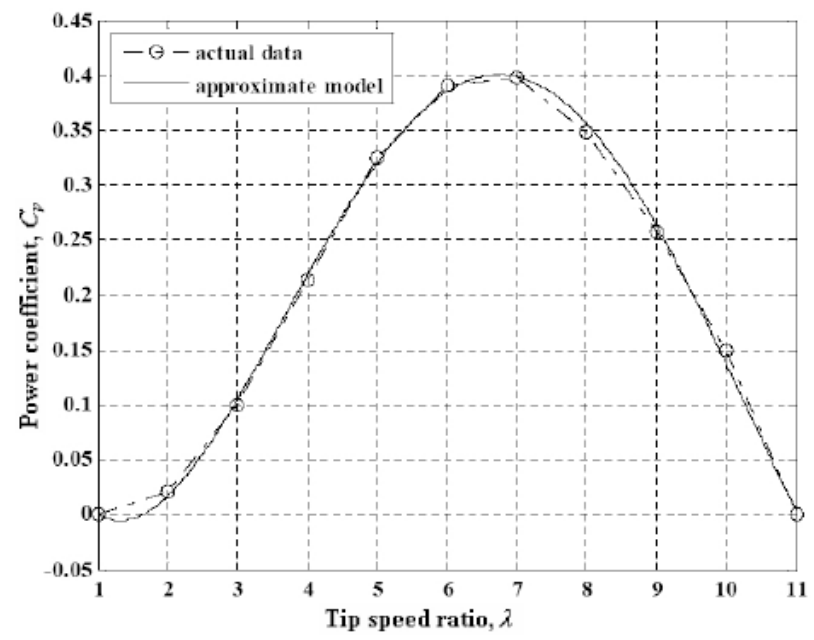

Fig. (2). Power coefficient as a function of tip-speed ratio. 


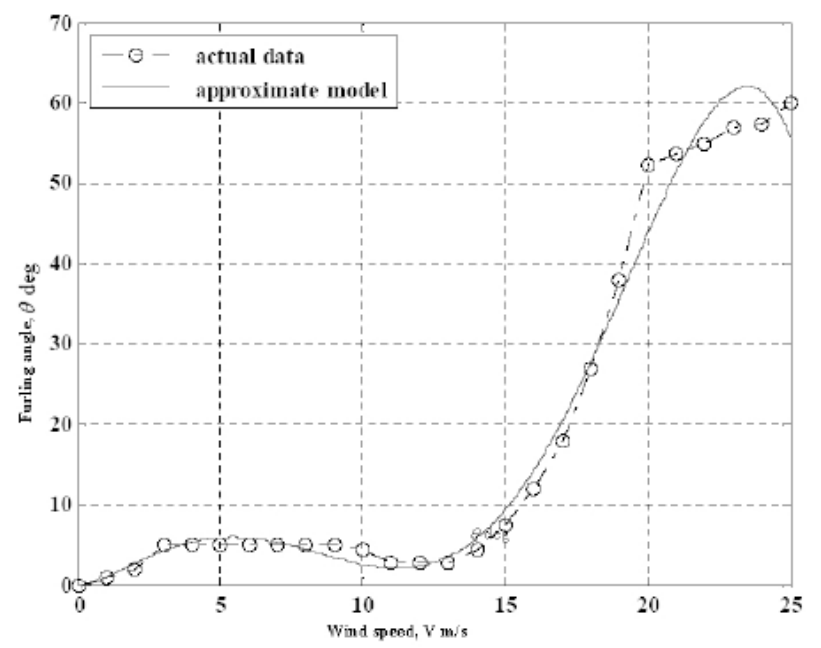

Fig. (3). Furling angle versus wind speed.

The continuous function of (4) is converted to a discrete equivalent with a zero order hold for 0.1 second sampling time. The discrete equivalent is given by [11]

$$
H(z)=\frac{0.003747 z+0.003652}{z^{2}-1.919 z+0.926}
$$

The output power of the wind turbine can be expressed as

$$
P_{\text {aero }}=0.5 \rho A C_{p}(\lambda) V^{3}
$$

where, $\rho$ is the air density $\left(\mathrm{kg} \cdot \mathrm{m}^{-3}\right)$ and $A$ is the rotor rotational area, i.e., $\pi R^{2}$.

The torque produced by the wind turbine is given by

$$
T_{w}=\frac{P_{\text {aero }}}{\omega_{m}}
$$

Substituting (6) in (7), the torque term can be expressed as

$$
T_{w}=\frac{0.5 \rho A C_{p}(\lambda) V^{3}}{\omega_{m}}
$$

When the wind speed increases, small wind turbines yaw to an angle $\theta$ along its horizontal axis because of the furling action. The effective wind velocity at the rotor plane in that case will be $V \cos \theta$ [2]. Incorporating the furling action, the theoretical rotational speed of the wind turbine can be written from (8) as

$$
\omega_{m}=\frac{0.5 \rho A C_{p}(\lambda)(V \cos \theta)^{3}}{T_{w}}
$$

This represents the reference speed of the WT rotor for a specific wind speed. The torque information required in (9) is obtained from the DC motor current.

A velocity PI algorithm was used to track the theoretical rotational speed of the wind turbine rotor. The output of the PI controller can be written as [25]

$$
u(t)=u(t-1)+K_{p} *[e(t)-e(t-1)]+\frac{K_{p} * T_{s}}{T_{i}} e(t)
$$

Where,

$K_{p} \quad$ is the proportional gain of the PID controller.

$T_{i} \quad$ is the integral time of the controller.

$T_{d} \quad$ is the derivative time of the controller.

$e(t)$ is the error between reference and actual control variable.

A flow chart for the controller loop and algorithm is given in Fig. 4.

\section{WIND TURBINE EMULATOR POWER ELEC- TRONICS}

A separately excited DC motor is used to represent the WT rotor and the parameters are given in Table 1. A DC motor operates more accurately at low speeds, thus ensuring accurate emulation at low wind speeds. The PC based controller triggers the silicon controlled rectifier through a

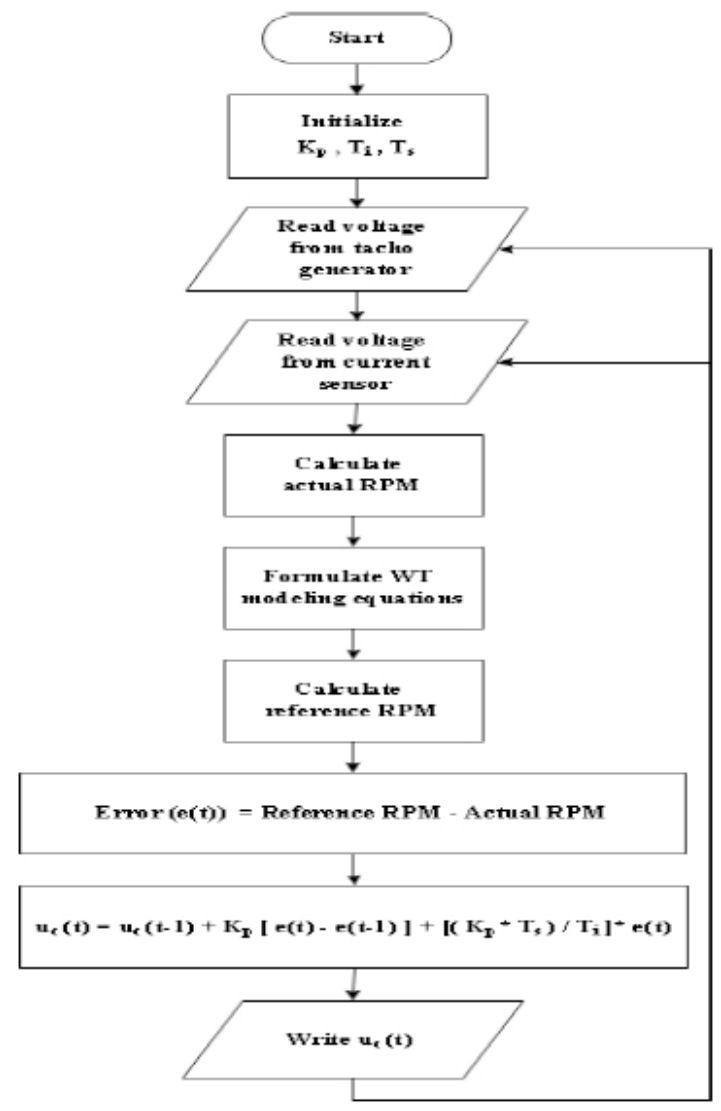

Fig. (4). Flow chart of the control loop.

Table 1. DC Motor Parameter

\begin{tabular}{|l|c|}
\hline Armature resistance & $0.4 \mathrm{ohm}$ \\
\hline Inertia & $0.026042 \mathrm{~kg}-\mathrm{m}^{2}$. \\
\hline Back emf constant & $73.167 \mathrm{v} / \mathrm{krpm}$ \\
\hline Torque coefficient & $0.0711 \mathrm{~kg} \cdot \mathrm{m} / \mathrm{A}$. \\
\hline
\end{tabular}


LabMaster I/O board. A tacho generator is used to measure the motor rotational speed and a current sensor is used to measure the motor armature current. The output of the phase controlled rectifier is filtered and applied to the motor armature while the motor field voltage is kept constant at 76 volt. An inertia disk representing the inertia of a real wind turbine rotor is coupled to the synchronous generator. A complete schematic of the wind turbine section of the emulator with peripheral is shown in Fig. (5).

\section{MAXIMUM POWER CONTROLLER ELEC- TRONIC CIRCUIT}

A Small Wind Turbine (SWT) system is very often used for remote and isolated locations, or in the absence of the electrical power grid. In such a scenario, it is always desirable to power the associated power electronics circuitry of the wind turbine from the wind turbine itself. The situation has been taken care of by an approach in which the necessary power for the power electronics components is generated from the wind. The output of the synchronous generator is first rectified by a 3-phase bridge rectifier and passed through a DC-DC converter. The buck-boost converter topology is selected since the variation of wind speed and expected output voltage are not known in advance. The duty ratio of the converter is controlled by a microcontroller (PIC 18F452) and the output of the converter is connected to a dump load. The maximum power controller is implemented through the PIC, which compares the actual TSR with an optimum TSR and uses the difference to control the pulse width modulation (PWM) duty ratio of the buck-boost converter in order to achieve maximum power extraction. An isolated supply using a single output $+5 \mathrm{~V}$ to $+15 \mathrm{~V}$ commercially available dc-dc converter is designed and implemented to power the opto-coupler and driver. The generator RPM is determined from its output voltage. The single-phase voltage of the generator is lowered using a transformer and converted into square wave using a Schmitt trigger. The square wave pulses are converted into an analog voltage using a frequency to voltage converter with a calibration equation described by
Generator frequency $=4.4271 *$

Voltage input to the PIC -0.2933

The analog voltage from the frequency to voltage converter is supplied to the microcontroller. The reference voltage for the Schmitt trigger is also generated using a voltage divider and output of the dc-dc converter. The variable frequency of the pulses is converted to voltage using an F/V converter IC. An amplifier stage is necessary to amplify the low voltage to $0-5 \mathrm{~V}$ range. A dual output $(+5$ to $+15 /-15)$ dc-dc converter is used to power the Schmitt trigger, F/V converter and amplifier. A fixed voltage regulator is used to supply the necessary +5 volts to the dc-dc converter and the PIC. A 3- $\Phi$ bridge rectifier is used to convert the ac voltage to $\mathrm{DC}$ and a variable resistor and zener diode combination is used to regulate the input DC voltage variation to the acceptable input voltage level of the fixed voltage regulator. The complete power electronics circuitry is divided into four stages, namely the buck-boost converter stage, power stage, driver stage, and RPM information extraction stage. To ensure maximum power production, the rotational speed of the WT is extracted from the RPM information extraction stage and used to calculate the TSR. The maximum power controller power electronics is presented in Fig. 6.

\section{MAXIMUM POWER CONTROLLER}

In order to extract the maximum power, an optimum TSR control is first selected. An optimum TSR of 7 is considered as the maximum power point (Fig. 2). It should be mentioned that the optimum TSR is not a constant, it can vary from one system to another. The actual TSR of the wind turbine is compared with the optimum TSR and the microcontroller generated PWM signals control the buck-boost converter in order to control the effective dump load connected to the system. The maximum power control algorithm is programmed through the PIC and interfaced with a PC through a serial port. MikroBasic 2.0.0.4 as a programming language and used to code the MPC algorithm of the emulator system.

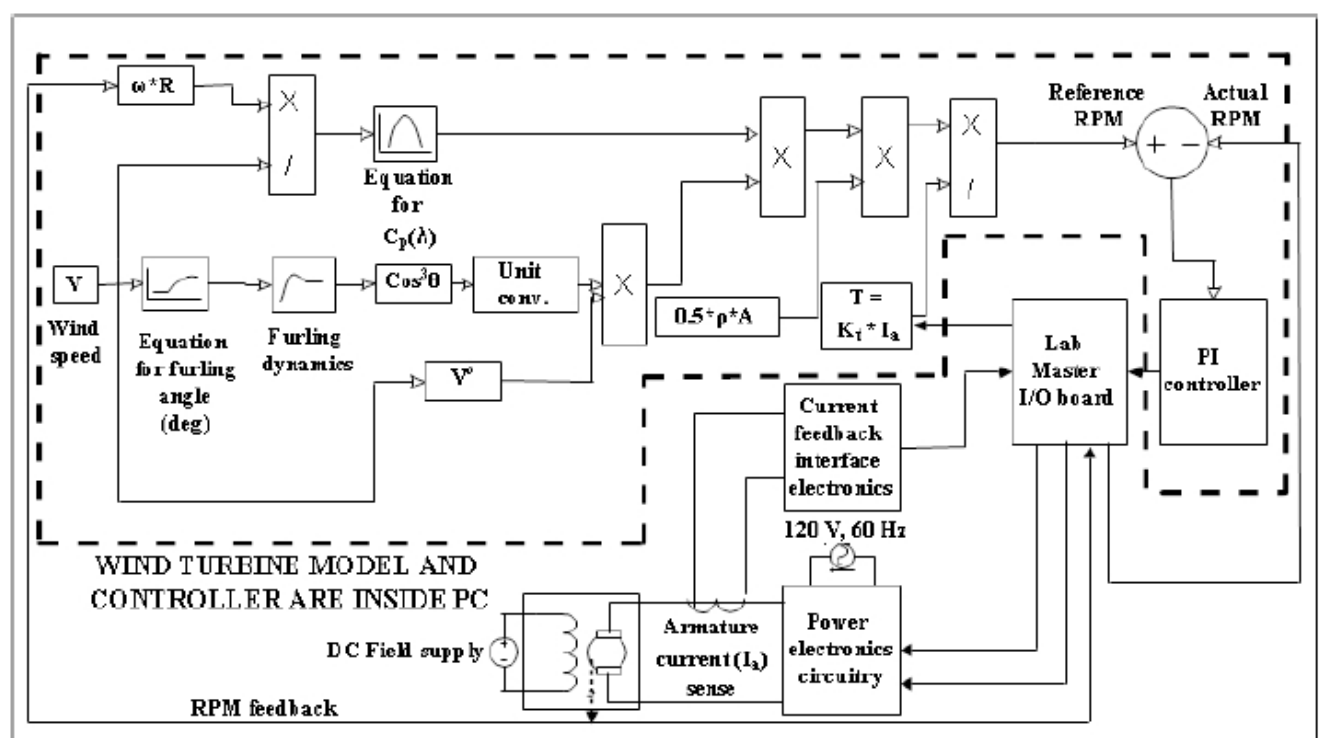

Fig. (5). Small wind turbine emulator structure with peripherals. 


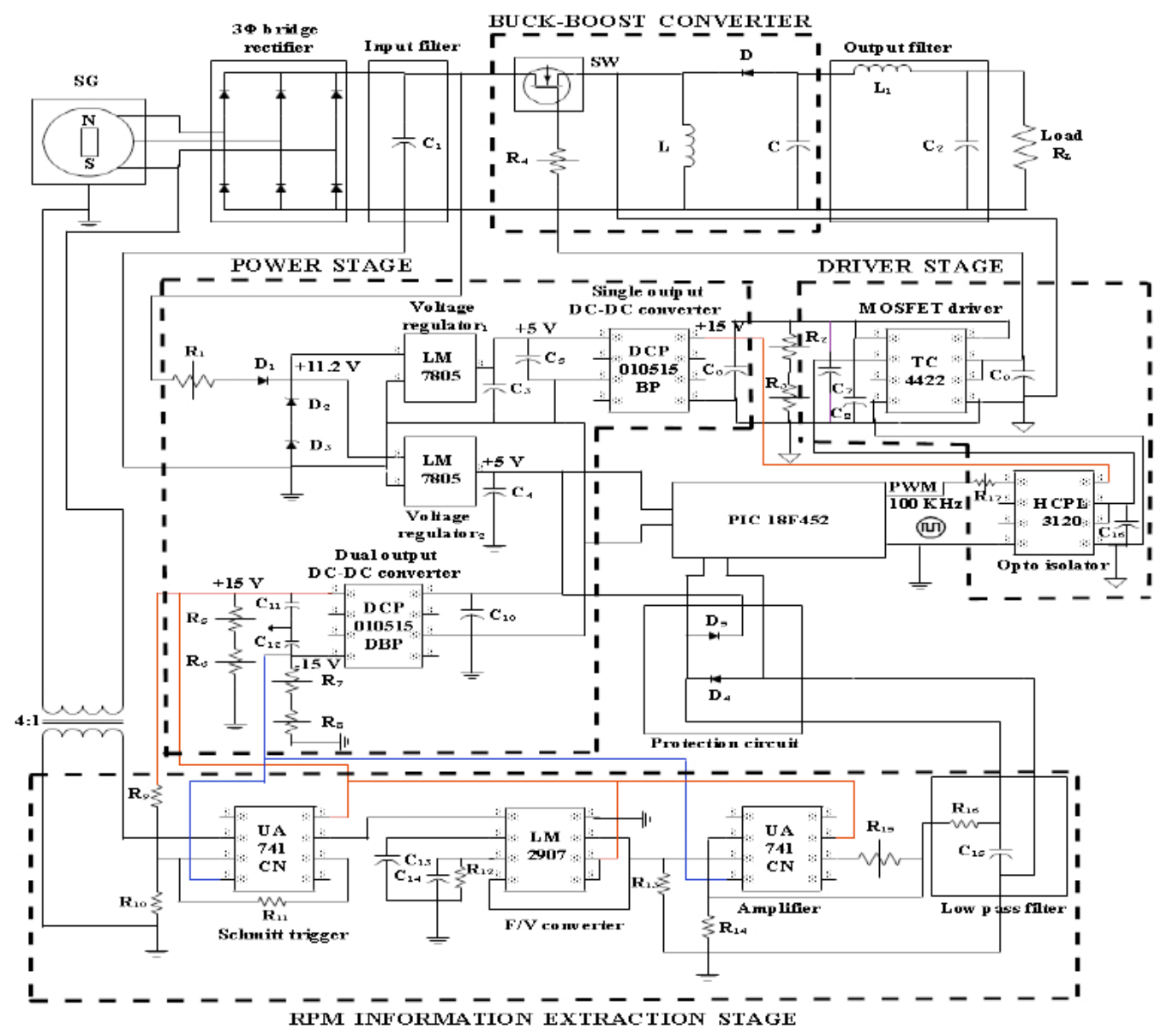

Fig. (6). Maximum power controller electronic circuit.

A terminal emulator (TERA TERM PRO) is used to provide communication between the PIC and PC. The basic structure of the maximum power controller and the complete flow diagram is shown in Fig. (7) and Fig. (8) respectively. Real time issues were identified during testing. For instance, a situation occured when the wind turbine was not rotating but the power electronics stage was $\mathrm{ON}$, or when suddenly the power was switched OFF to the power electronics stage but the wind turbine was rotating. To address such issues, the MPC code was modified so that it will check the input condition and jump to an appropriate section of the program as required. Also to display various data value onto the PC screen, a separate routine was created to send data to the serial port while the main loop was executing.

\section{RESULTS}

The small wind turbine emulator and the maximum power controller described above were implemented and tested in the laboratory environment. Digital PI controllers were designed for both WTE and the MPC to ensure that the speed of the separately excited DC motor was the same as the required rotational speed of the wind turbine rotor and that it corresponded to the optimum TSR of the wind turbine. It was expected that the emulator would reflect the characteristic of a wind turbine and ensure maximum power extraction by maintaining the optimum TSR. The results for two constant wind speed of $7 \mathrm{~m} / \mathrm{s}$ and $8 \mathrm{~m} / \mathrm{s}$ are presented in Figs. (9-24).

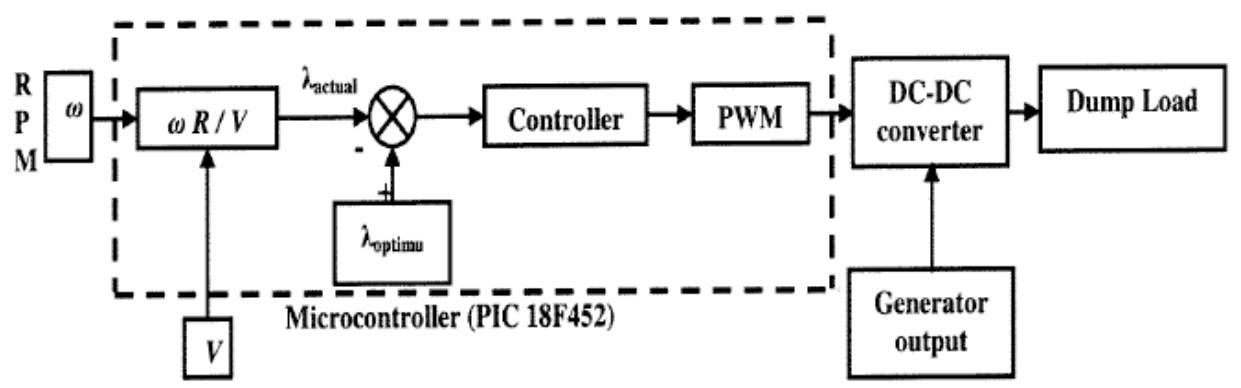

Wind speed

Fig. (7). Structure of the maximum power controller. 


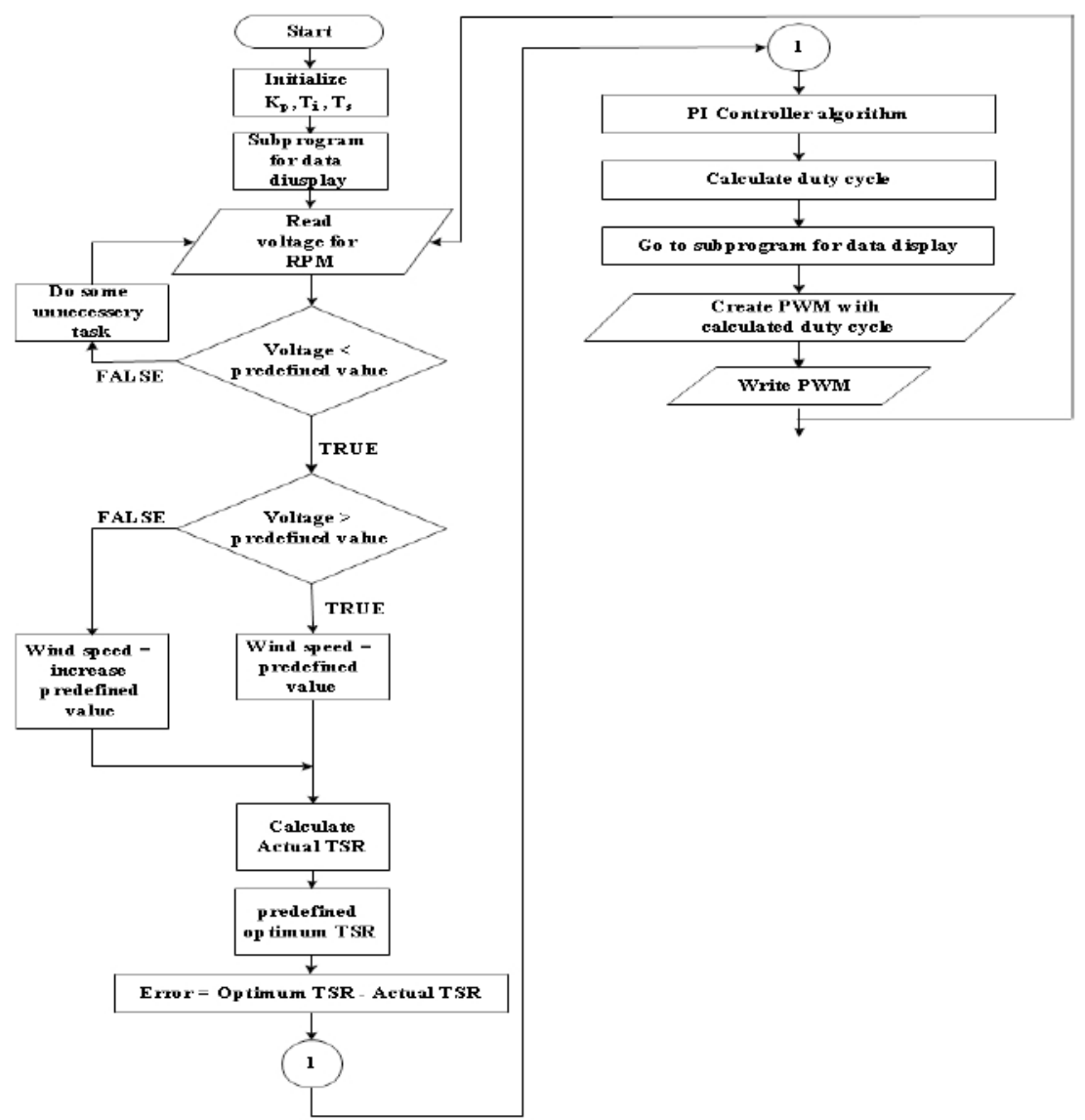

Fig. (8). Flow diagram of the maximum power controller algorithm.
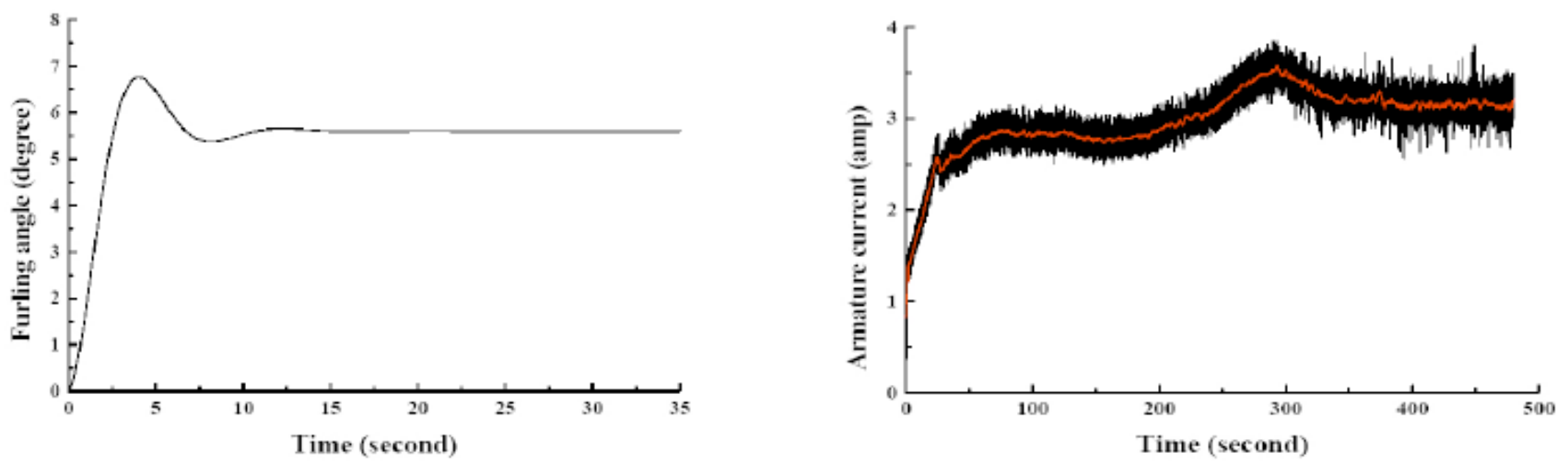

Fig. (9). Expected furling dynamics $(7 \mathrm{~m} / \mathrm{s})$.

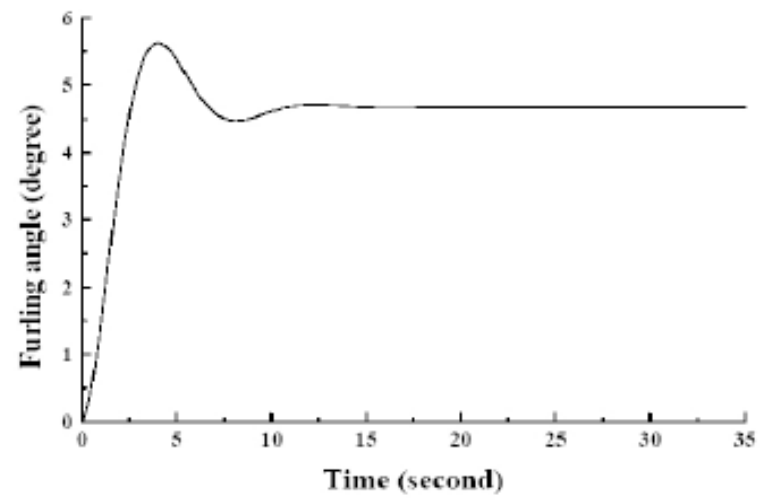

Fig. (11). Variation of armature current $(7 \mathrm{~m} / \mathrm{s})$.

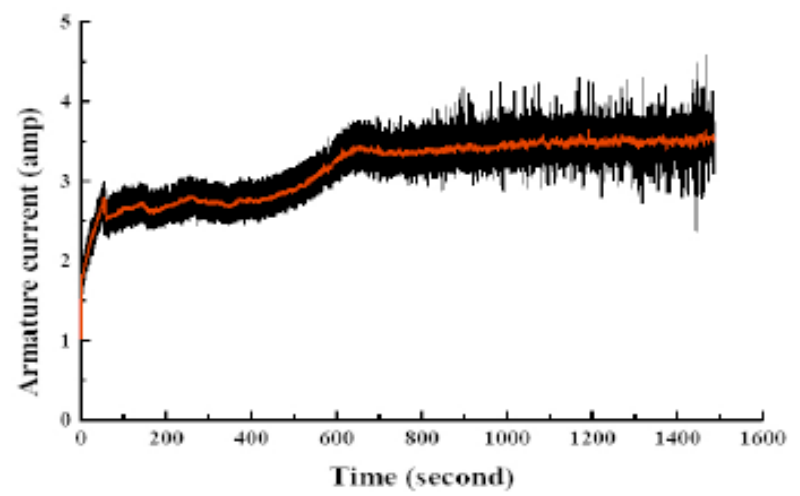

Fig. (10). Expected furling dynamics $(8 \mathrm{~m} / \mathrm{s})$.

Fig. (12). Variation of armature current $(8 \mathrm{~m} / \mathrm{s})$. 


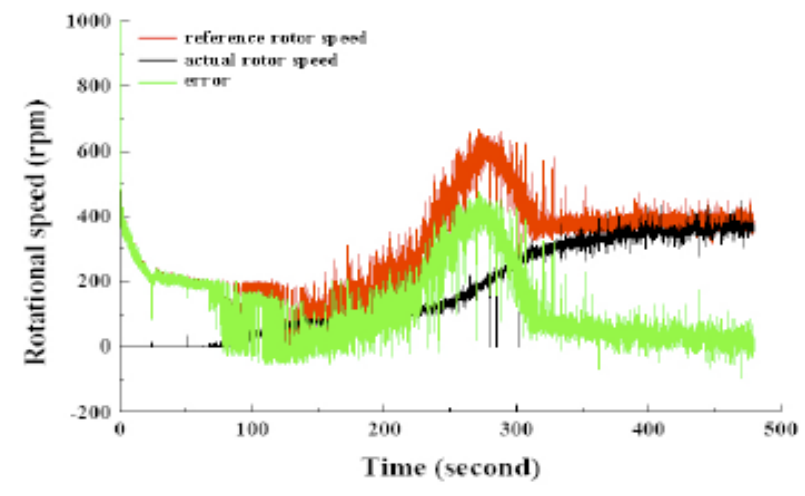

Fig. (13). Variation of RPM $(7 \mathrm{~m} / \mathrm{s})$.

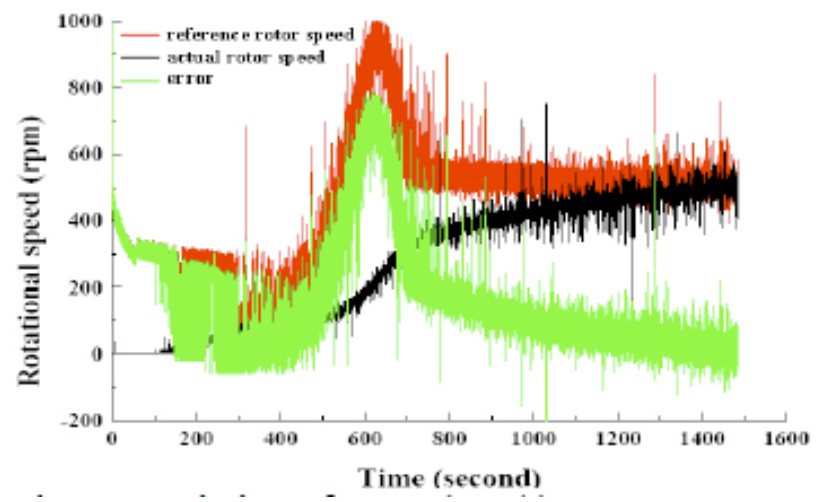

Fig. (14). Variation of RPM $(8 \mathrm{~m} / \mathrm{s})$.

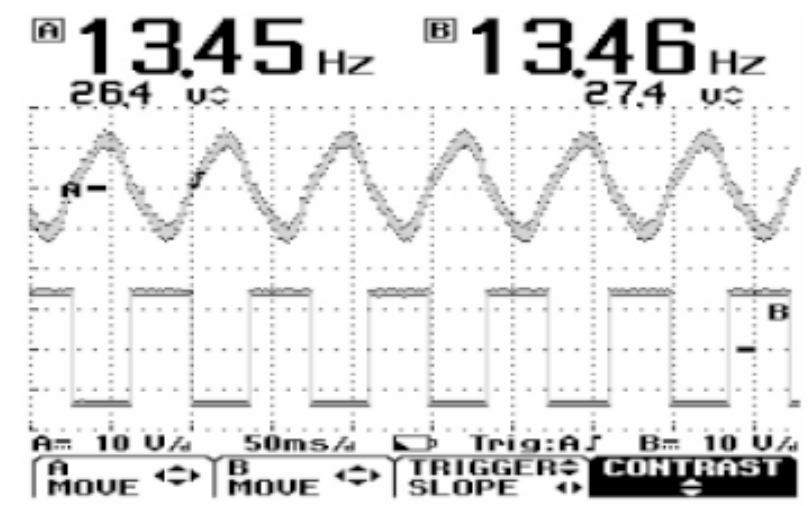

Fig. (15). Transformer (upper) and Schmitt trigger (lower) output (7 $\mathrm{m} / \mathrm{s})$.

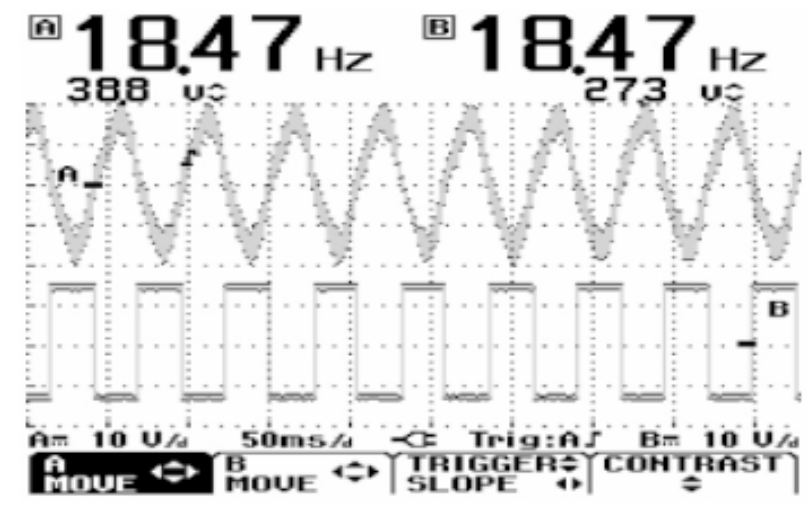

Fig. (16). Transformer (upper) and Schmitt trigger (lower) output (8 $\mathrm{m} / \mathrm{s})$.

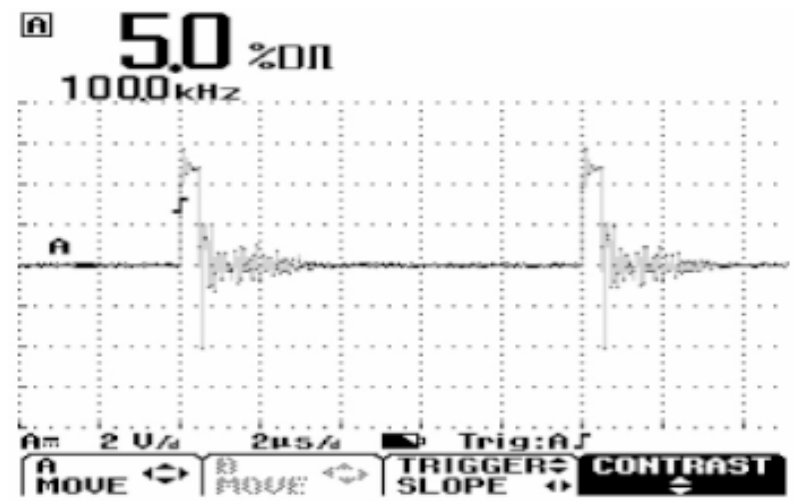

Fig. (17). PWM output from the PIC $(7 \mathrm{~m} / \mathrm{s})$.

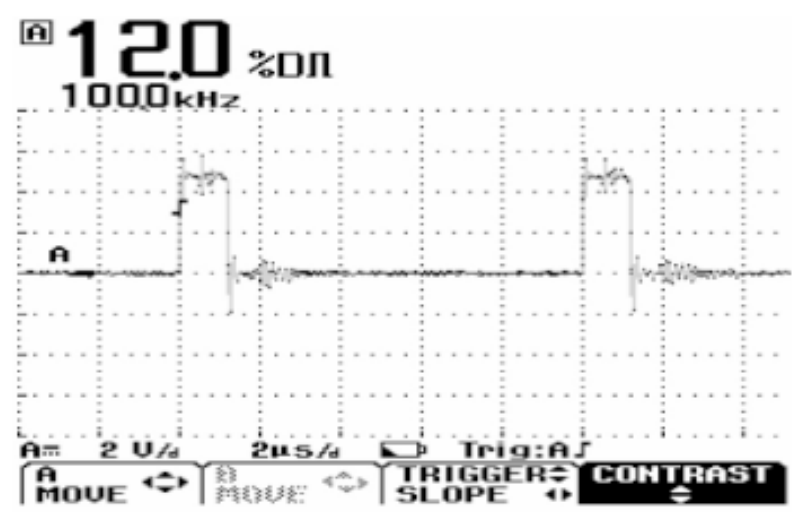

Fig. (18). PWM output from the PIC $(8 \mathrm{~m} / \mathrm{s})$.

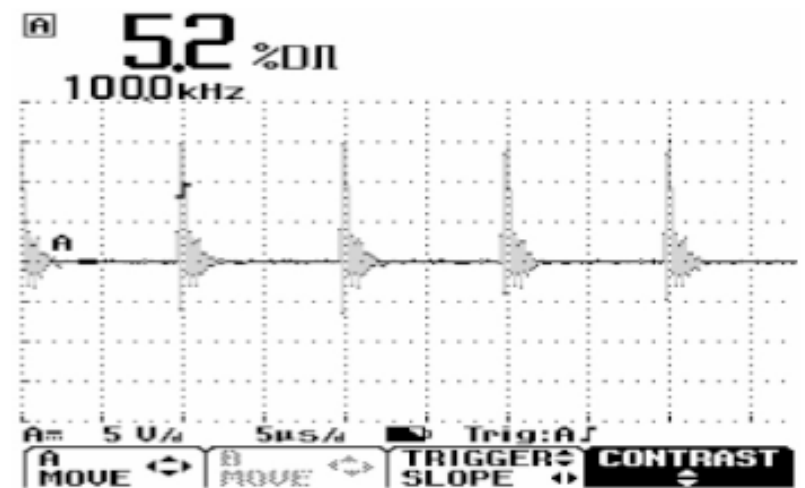

Fig. (19). Gate drive signal for the MOSFET switch $(7 \mathrm{~m} / \mathrm{s})$.

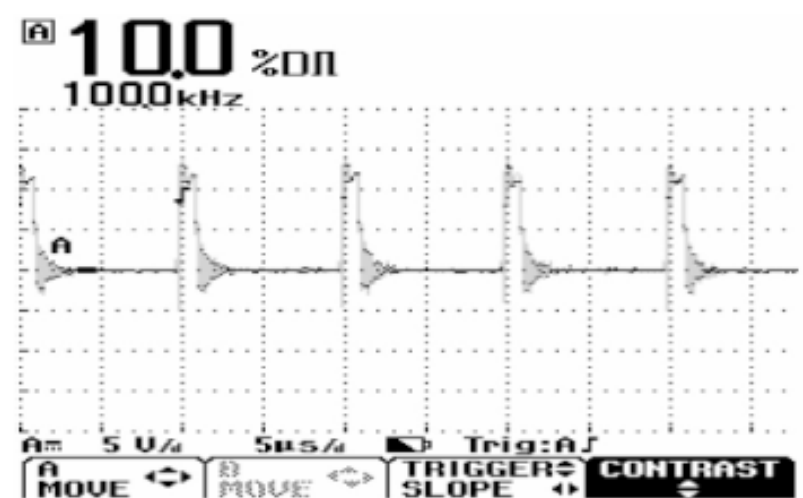

Fig. (20). Gate drive signal for the MOSFET switch $(8 \mathrm{~m} / \mathrm{s})$. 


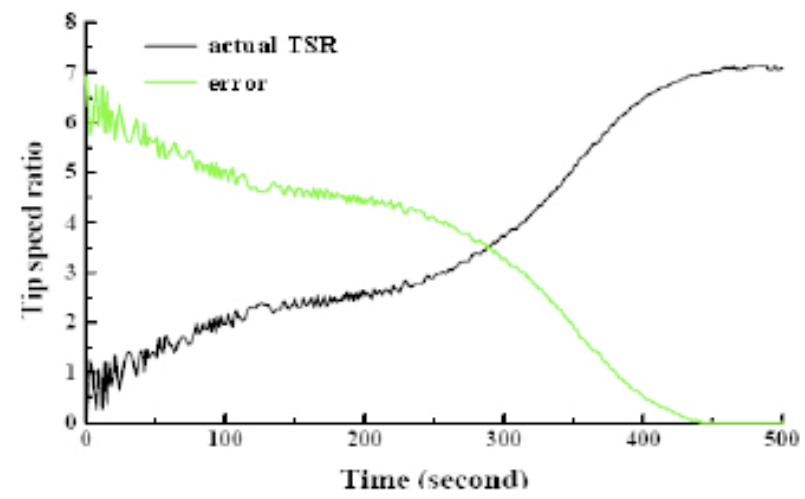

Fig. (21). Variation of TSR $(7 \mathrm{~m} / \mathrm{s})$.

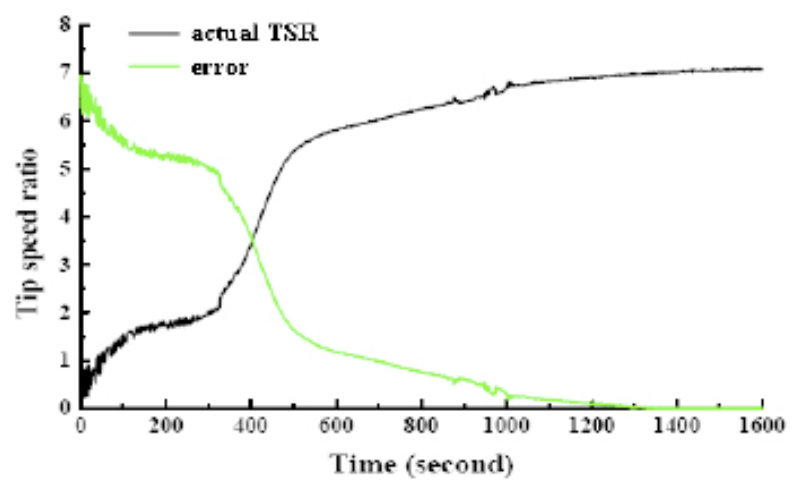

Fig. (22). Variation of TSR $(8 \mathrm{~m} / \mathrm{s})$.

Fig. (9) and Fig. (10) show the expected furling dynamics of the wind turbine for 7 and $8 \mathrm{~m} / \mathrm{s}$ wind speed respectively. Within 10 seconds of the constant wind speed, the rotor reached a stable state at a furling angle of $5.3^{\circ}$ and $4.4^{\circ}$, which corresponds to the value obtained in (3). The limitation of the armature current is of importance in order to protect the motor armature. The variation in armature current characteristic corresponding to the change in wind speed was recorded and averaged to generate a uniform distribution over the entire wind speed range. It can be seen that the proposed controller limits the amplitude of the armature current of the DC motor below 4 ampers and 5 amperes for $7 \mathrm{~m} / \mathrm{s}$ and $8 \mathrm{~m} / \mathrm{s}$ wind speed respectively as presented in Fig. (11) and Fig. (12). With a constant wind speed, the motor started to draw current from the main, while no unwanted overshoot of the current was observed. The experimental results thus prove that the current limitation functions well, and the controller has a good performance, independent of the speed and motor dynamics. The corresponding reference rotor speed, actual rotational speed and error are shown in Fig. (13) and Fig. (14). It is observed that with a constant wind speed, the motor speed follows the reference rotor speed and the error becomes more or less zero within 500 seconds and $1400 \mathrm{sec}-$ onds for 7 and $8 \mathrm{~m} / \mathrm{s}$ respectively. The performance of the proposed design of the maximum power controller is depicted through Fig. (15-24).

The signals from the transformer (upper trace) and schmitt trigger (lower trace) are given in Fig. (15) and Fig. (16) respectively. It can be seen that there is a good agreement between the experimental frequency and the expected frequency. The PWM signal generated by the PIC shows harmony with the driving signal to the MOSFET gate (Fig. 17-20). The ringing observed on the PWM signal as well as the driving signal is due to the electromagnetic noise from other stages of the system. In order to investigate the maximum power extraction from the developed small wind turbine emulator, the TSR was recorded for each wind speed. Fig. $(\mathbf{2 1}, \mathbf{2 2})$ shows that the TSR reached an optimum TSR of 7 as predicted from Fig. (1a) and remained more or less constant.

Although a step change in wind speed is not very realistic, the change can be used to investigate the system dynamics from the point of the control of the system. Consequently, the emulator model was subjected to a step increase in wind speed from $7 \mathrm{~m} / \mathrm{s}$ to $8 \mathrm{~m} / \mathrm{s}$ (Fig. 23a, b) represents the expected furling dynamics of the wind turbine. Within $10 \mathrm{sec}-$ onds of the step input, the rotor reached a stable state at a furling angle of $4.3^{0}$, which again corresponds to the value obtained in (3). The corresponding reference rotor speed, actual rotational speed of the motor and error are shown in Fig. (23c). It is observed that after a step, the motor speed follows the reference rotor speed and the error becomes more or less zero. Fig. (25) represents the variations of the arma-

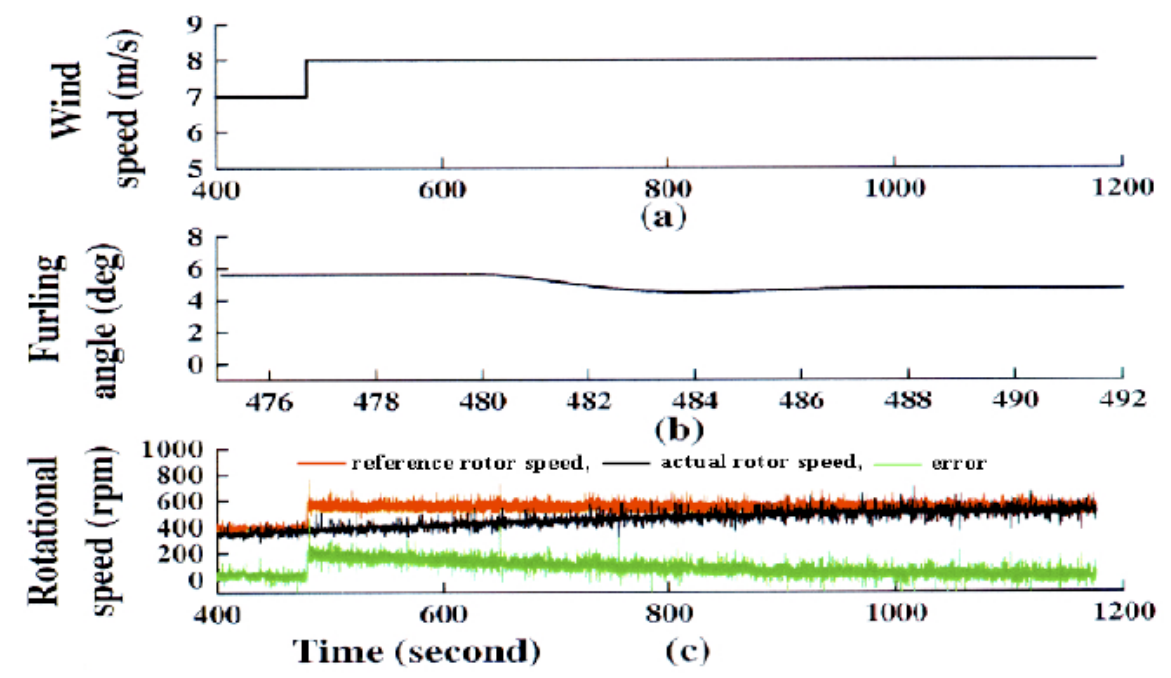

Fig. (23). (a) Wind speed profile applied to the wind turbine emulator (b) Furling dynamics. (c) Rotor rotational speed. 

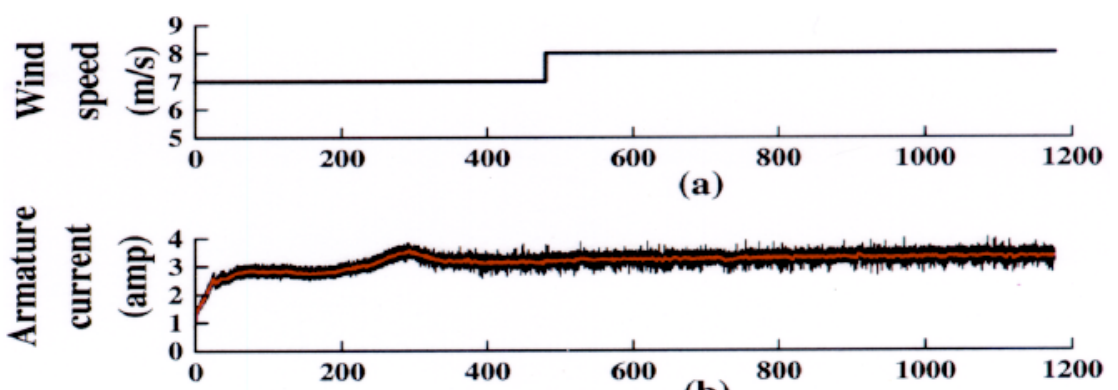

(b)

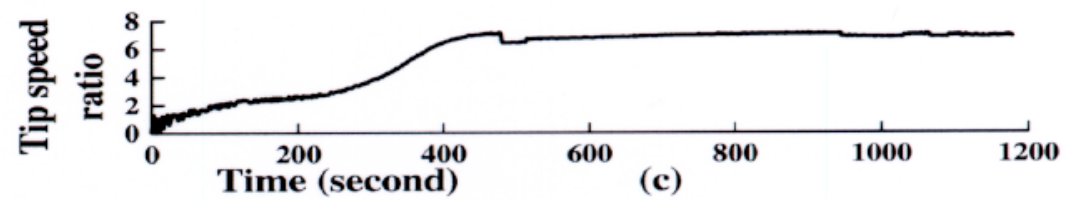

Fig. (24). (a) Wind speed profile applied to the wind turbine emulator. (b) Armature current, (c) Variation of TSR with time.

ture current and TSR with time. With the step change in wind speed (Fig. 23a, 24a), the armature current increases slightly as shown in Fig. 24b. The measured current was filtered using averaging technique. The TSR for the step change in wind speed was recorded (Fig. 24c). It was found that as soon as the wind speed changed, the TSR of the wind turbine dropped, then started to increase, and finally reached an optimum TSR of 7 (Fig. 24c) and remained more or less constant as predicted. The results presented above for the WTE and MPC reveal that the developed WTE is able to accurately represent small wind turbine behaviour and is capable of extracting the maximum power from the system.

\section{CONCLUSIONS}

The development of an isolated wind turbine emulator for small wind turbine system with furling and rotor dynamics has been presented in this paper. The proposed system along with required power electronics and control scheme were designed, implemented and tested in the laboratory. Maximum power extraction was ensured by operating the wind turbine at an optimum tip-speed ratio. Test results showed acceptable performance in terms of wind turbine and maximum power controller characteristic. This operational wind turbine emulator can be used for further research on a small wind energy conversion system and provides a test-bed to investigate and develop other control strategies.

\section{ACKNOWLEDGMENT}

The authors' would like to thank the National Science and Engineering Research Council (NSERC) Canada for providing financial support of this research.

\section{REFERENCES}

[1] Hoffmann, R.; Mutschler, P. The Influence of Control Strategies on the Energy Capture of Wind Turbines, In: Industry Applications Conference, Rome, Italy, October 8-12, 2000.

[2] Bialasiewicz, J.T. Furling Control for Small Wind Turbine Power Regulation, In: Industrial Electronics, Rio de Janeiro, Brasil, June 9-12, 2003.

[3] Muljadi,E.; Forsyuth, T; Butterfield, C.P. Soft-stall control vs. Furling control for small wind turbine power regulation, pp. 12 NREL Report No. CP-500-25100, 1998.

[4] Iqbal., M.T. Modeling and Simulation of a Small Wind Turbine, In: $13^{\text {th }}$ IEEE Newfoundland Electrical and Computer Engineer Conference. St. John's, Newfoundland, November 12, 2003.
[5] Arifujjaman, Md.; Iqbal, M.T.; Quaicoe, J.E. Energy capture comparison of a small wind energy conversion system. Applied Energy, 2008, $85,41-51$.

[6] Jie, W.; Yanhao, X. Dynamic simulation method for wind turbine based on induction motor. Journal of South China University of Technology, 2005, 33, 46-49.

[7] Pierik, J.T.G.; Hoeijmakers, M.J.; Vleeshouwers, J.M.; Van Engelen, T.G.; Baltus, C.W.A.; Veltman, A.T.; Warmenhoven, A. A Variable Speed System with Integral Control for Wind Turbines (IRFLET): Design of the Test-rig, In: European Wind Energy Conference, Amsterdam, Netherlands, October 14-18, 1991.

[8] Battaiotto, P. E.; Mantz, R. J.; Puleston, P. F. A wind turbine emulator based on a dual DSP processor system. Control Engineering Practice, 1996, 4, 1261-1266.

[9] Jian, Lu.; Cheng Xu, W. The Simulation System of Wind Turbine Performance Using a Microcontroller Controlled SCR_DC Motor, In: International Conference on Electrical Machines, Beijing, China, August 1987.

[10] Farret, F. A.; Gules, R.; Marian, J. Micro-Turbine Simulator Based on Speed and Torque of a DC Motor to Drive Actually Loaded Generators. In: IEEE International Caracas Conference on Devices, Circuits and Systems, Universidad Simón Bolívar, Caracas, Venezuela, December 12-14, 1995.

[11] Chang, L.; Doraiswami, R.; Boutot, T.; Kojabadi, H. Development of a Wind Turbine Simulator for Wind Energy Conversion Systems. In: IEEE Canadian Conference on Electrical and Computer Engineering, Halifax, Canada, May 7-10, vol. 1, pp. 550-554, 2000.

[12] Kojabadi, H.M.; Chang, L.; Boutot, T. Development of a novel wind turbine simulator for wind energy conversion systems using an inverter-controlled induction motor. IEEE Transactions on Energy Conversions, 2004, 19, 547-552.

[13] Kojabadi, H.M.; Chang, L. A novel steady state wind turbine simulator using an inverter controlled induction motor. Wind Engineering, 2004, 28, 433-446.

[14] Nunes, Alexandre; Seixas, C.; Paulo Fernando Cortizo; Porfírio Cabaleiro Silva; Selênio Rocha. Wind Turbine Simulator Using a DC machine and a power reversible converter. In: International Conference on Electrical Machines, Adelaide, Australia, September 14-16, 1993.

[15] Rodríguez-Amenedo, J.L.; Rodríguez-García, J.L.; Burgos, J.C.; Chinchilla, M.; Arnalte, S.; Veganzones, C. Experimental Rig to Emulate Wind Turbines. In: International Conference on Electrical Machines, Istanbul, Turkey, September 2-4, 1998.

[16] Rabelo, B.; Hofmann, W.; Gluck, M. Emulation of the Static and Dynamic Behaviour of a Wind-Turbine with a DC-machine Drive, In: IEEE Power Electronics Specialists Conference, Anchen, Germany, June 20-26, 2004.

[17] Diop, D.; Nichita, C.; Belhache, J. J.; Dakyo, B.; Ceanga, E. Modeling variable pitch HAWT characteristics for a real time wind turbine simulator. Wind Engineering, 1999, 23, 225-243.

[18] Barrero, F.; Mora, J.L.; Perales, M.; Marchante, A.; Galvàn, E.; Carrasco, J.M.; Torralba, A.; Franquelo, L.G. A Test-Rig to Evaluate a Wind Turbine Generation Control System Based on DSP. In: 
European Conference on Power Electronics and Applications, Trondheim, Noruega, September 1997.

[19] Diop, D.; Nichita, C.; Belhache, J. J.; Dakyo, B.; Ceanga, E. Error evaluation for models of real time wind turbine simulators. Wind Engineering, 2000, 24, 203-221.

[20] Arifujjaman, Md.; Iqbal, M.T.; Quaicoe, J.E. San Isolated Small Wind Turbine Emulator. In: Canadian Conference on Electrical and Computer Engineering, Ottawa, Canada, May 7-May 10, 2006.

[21] Muljadi, E.; Forsyuth, T.; Butterfield, C.P. Soft-Stall Control Versus Furling Control for Small Wind Turbine Power Regulation. In: Windpower Conference, Bakersfield, California, USA, April 27May $1,1998$.

[22] Corbus, D.; Prascher, D. Analysis and Comparison of Test Results from the Small Wind Research Turbine Test Project. In: AIAA
Aerospace Sciences Meeting and Exhibit, Reno, Nevada, January $10-13,2005$

[23] Jr. Eggers, A. J.; Chaney, K.; Holley, W.E.; Ashley, H.; James Green, H.; Sencenbaugh, J. Modeling of Yawing And Furling Behavior of Small Wind Turbines. In: The American Institute of Aeronautics and Astronautics (AIAA) and the American Society of Mechanical Engineers, Reno, Nevada, January 10-13, 2000.

[24] Roberts, J. Micro Wind Energy Systems in Harsh Environments: Failure Analysis of Small Wind Turbines at Remote Sites in Labrador, M. Eng. Thesis, Memorial University of Newfoundland, St. John's, NL, Canada, 2009.

[25] Iqbal, M.T.; Coonick, A.H.; Freris, L.L. Dynamic Control of a Stand Alone Wind Turbine, In: British Wind Energy Association Energy Conference, Sterling, UK, June 15-17, 1994.

(c) Md. Arifujjaman; Licensee Bentham Open.

This is an open access article licensed under the terms of the Creative Commons Attribution Non-Commercial License (http://creativecommons.org/licenses/by-nc/3.0/) which permits unrestricted, non-commercial use, distribution and reproduction in any medium, provided the work is properly cited. 